\title{
NOTAS INTRODUTÓRIAS SOBRE OS SABERES CONSTRUÍDOS A PARTIR DA TRADIÇÃO ORAL DA COMUNIDADE QUILOMBOLA DE ONZE NEGRAS DO CABO DE SANTO AGOSTINHO- PE
}

\author{
Ronalda Adriana dos Santos da Silva ${ }^{1}$ \\ Ivaneia Maria de Lima² \\ Maria José da Silva ${ }^{3}$ \\ Cristiano Leonardo Martins Oliveira ${ }^{4}$ \\ Diógenes José Gusmão Coutinho ${ }^{5}$
}

Resumo: A inquietação pessoal para investigar tal temática surge da necessidade de acompanhar e refletir sobre a interlocução entre o currículo formal escolar e os saberes tradicionais dos povos quilombolas tendo a oralidade como fio histórico para perpetuação destes conhecimentos entre os quilombolas, especificamente sobre a Comunidade Quilombola Onze Negras localizada no Cabo de Santo Agostinho. Para tanto, figurou como objetivo geral deste trabalho apresentar uma breve incursão histórica e semântica sobre o Quilombo on trato do currículo e a oralidade com atenção especial para a Comunidade Remanescente de Quilombo Onze Negras, localizada no Cabo de Santo AgostinhoPernambuco. Para dirimir tais questões, foram utilizadas as pesquisas, documental, bibliográfica como caminho metodológico que melhor se relaciona

\footnotetext{
${ }^{1}$ Graduação curso de licenciatura plena em pedagogia - Universidade Estadual Vale do Acaraú, pós-graduação lato sensu em gestão e psicopedagogia institucional - faculdade européia de administração e marketing, mestranda internacional em ciências da educação, pela faculdade Atenas College University. E-mail: adriana-santos2011@hotmail.com.br.

${ }^{2}$ Graduada em pedagogia pela Universidade Vale do Acaraú-UVA. e Especialização em Gestão Escolar pela Faculdade Pitágoras de Belo Horizonte, mestranda internacional em ciências da educação, pela faculdade Atenas College University. E-mail: ivaneialima36@gmail.com.
}

3 Graduada em pedagogia pela UPE - Faculdade de Pernambuco. Especialização em Psicopedagoga Clínica e Institucional pela FAJOLCA- Faculdade José Lacerda Filho de Ciências Aplicada, mestranda internacional em ciências da educação, pela faculdade Atenas College University. E-mail: mariajose-045@hotmail.com.

\begin{tabular}{lllcc}
${ }^{4}$ Graduação: & Licenciatura & \multicolumn{1}{c}{ Plena } & em & $\begin{array}{c}\text { Geografia } \\
\text { Instituição: FAMASUL- }\end{array}$ \\
Faculdade de & Formação de & Professores da & Mata Sul \\
Especialização: & Psicopedagogia & Clínica & e & Institucional
\end{tabular} Instituição: FAJOLCA- Faculdade José Lacerda Filho de Ciências Aplicadas. mestrando internacional em ciências da educação, pela faculdade Atenas College University. E-mail: cristianolmoliveira@gmail.com.

${ }^{5}$ Graduado em Biologia pela UFRPE. Doutor em Biologia pela UFPE. Professor do Mestrado ALPHA. E-mail: alphadiogenes@gmail.com. 
com tal temática e com o intuito de responder essas inquietações iniciais. Tal investigação se consubstanciou a partir de uma inquietação pessoal para dar conta de uma lacuna acadêmica que referia-se à interlocução entre os saberes, fruto da tradição oral própria dos grupos remanescente de quilombos e os conhecimentos formais trazidos a partir do currículo escolar, especialmente para entender essa relação no lócus da Comunidade Quilombola Onze Negras localizada no Cabo de Santo Agostinho. Uma investigação preliminar sobre o tema nas bases de dados Sucupira, da USP e da Universidade Federal de Pernambuco mostra poucas produções acadêmicas sobre o universo citado, e nenhuma que trate da díade-currículo escolar e saberes tradicionais quilombola no orbe da Comunidade situada no Cabo de Santo Agostinho. O ineditismo do tema traz uma relevância à pesquisa no âmbito acadêmico local e nacional.

\section{INTRODUCTORY NOTES ON THE KNOWLEDGE CONSTRUCTED A PART OF THE ORAL TRADITION OF THE QUILOMBOLA COMMUNITY OF ELEVEN BLACK OF CABO DE SANTO AGOSTINHO- PE}

Palavras-Chave: Educação. Currículo formal. Oralidade. Quilombo.

Abstract: The personal concern to investigate such a theme arises from the need to monitor and reflect on the interlocution between the formal school curriculum and the traditional knowledge of quilombola peoples, with orality as a historical thread for the perpetuation of this knowledge among quilombolas, specifically about the Quilombola Onze Negras Community located in Cabo de Santo Agostinho. To this end, the general objective of this work was to present a brief historical and semantic incursion on Quilombo in terms of curriculum and orality with special attention to the Remaining Community of Quilombo Onze Negras, located in Cabo de Santo Agostinho-Pernambuco. To resolve these questions, documentary and bibliographic research was used as the methodological path that best relates to this theme and in order to answer these initial concerns. Such investigation was based on a personal concern to deal with an academic gap that referred to the interlocution between the knowledge resulting from the oral tradition typical of the remaining quilombos groups and the formal knowledge brought from the school curriculum, especially to understand this relationship in the locus of the Quilombola Onze Negras community located in Cabo de Santo Agostinho. A preliminary investigation on the topic in the Sucupira, USP and Federal University of Pernambuco databases shows few academic productions about the mentioned universe, and none that deals with the dyad-school curriculum and traditional quilombola knowledge in the community orb located in Cabo de Saint Augustine. The novelty of the theme brings relevance to research at the local and national academic level

Keywords: Education. Formal curriculum. Orality. Quilombo. 


\section{INTRODUÇÃO}

A inquietação pessoal para investigar tal temática surgiu da necessidade de acompanhar e refletir sobre a interlocução entre o currículo formal escolar e os saberes tradicionais dos povos quilombolas tendo a oralidade como fio histórico condutor para perpetuação destes conhecimentos entre os quilombolas, especificamente sobre a Comunidade Quilombola Onze Negras localizada no Cabo de Santo Agostinho.

Adentrar o espaço simbólico da Comunidade em tela para uma observação direta sobre a constituição da realidade social, e sua interlocução entre a escola e saberes tradicionais destes sujeitos é se engajar em uma experimentação de percepções cheia de contrastes pedagógicos, históricos, sociais, culturais e políticos. Assim, essa pesquisa entremeada pela motivação pessoal, também, representa uma resposta ao lugar acadêmico para a narrativa dos sujeitos quilombolas e suas leituras sobre o mundo.

Sopesar as comunidades tradicionais quilombolas e dar voz aos seus sujeitos, trazendo para a discussão, o currículo tradicional e os saberes ancestrais destes sujeitos, se possível, perceber in lócus o ponto de ambívio entre os dois temas, é também, refletir sobre a possibilidade da escola, de fato, trabalhar à diversidade, a partir de um currículo escolar hibrido que respeite, o arcabouço social e histórico de cada sujeito que se encontra nela. Ainda que, as hipóteses iniciais deste trabalho apontem para o completo distanciamento entre o currículo formal escolar e interlocução com os saberes dos seus alunos moradores da comunidade quilombola.

Para tanto, figurou como objetivo geral deste trabalho apresentar uma breve incursão histórica e semântica sobre o Quilombo no trato do currículo e a oralidade com atenção especial para a Comunidade Remanescente de Quilombo Onze Negras, localizada no Cabo de Santo Agostinho- Pernambuco.

A problemática inicial deste trabalho gira em torno de compreender de que modo os saberes ancestrais transmitidos a partir da tradição oral da população 
quilombola Onze Negras se relaciona com o currículo escolar. Para tanto, cabe a referenciar a existência da Escola Municipal Padre Henrique Vieira no interior da localidade citada. Aproveitando a oportunidade, cabe a ressalva que este artigo é parte introdutória da investigação de mestrado sobre a relação da referida comunidade e sua imbricação entre o currículo formal e as construções orais engendradas pela comunidade Onze Negras.

No que concerne a hipótese para a investigação posterior, própria do lócus do mestrado, aduz que o currículo da Escola Municipal Padre Henrique Vieira não permite uma relação profícua entre os saberes tradicionais advindos dos seus alunos quilombolas, tornando esses conhecimentos de caráter folclórico, e ignorando a dinâmica social própria da comunidade Onze Negras. Com igual atenção infere em uma segunda hipótese que a escola municipal inserida na Comunidade quilombola Onze Negras não se aproxima dos anseios dos seus alunos, refletindo um currículo distanciado dos saberes tradicionais próprio dos alunos e moradores.

Para dirimir tais questões levantadas no orbe do mestrado será utilizada pesquisa documental, bibliográfica e de campo de base etnográfica qualitativa como o caminho metodológico que melhor se relaciona com tal temática e com o intuito de responder essas inquietações iniciais.

Tal investigação se consubstanciou a partir de uma inquietação pessoal e dar conta de uma lacuna acadêmica que refere-se a interlocução entre os saberes, fruto da tradição oral própria dos grupos remanescente de quilombos e os conhecimentos formais trazidos a partir do currículo escolar, especialmente para entender essa relação no lócus da Comunidade Quilombola Onze Negras localizada no Cabo de Santo Agostinho. Uma investigação preliminar sobre o tema nas bases de dados Sucupira, da USP e da Universidade Federal de Pernambuco mostra poucas produções acadêmicas sobre o universo citado, e nenhuma que trate da díade- currículo escolar e saberes tradicionais quilombola no orbe da Comunidade situada no Cabo de Santo Agostinho. O ineditismo do tema traz uma relevância à pesquisa no âmbito acadêmico local e nacional. 
Sopesar as comunidades tradicionais quilombolas e dar voz aos seus sujeitos, trazendo para a discussão, o currículo tradicional e os saberes ancestrais destes sujeitos, se possível, perceber in lócus o ponto de ambívio entre os dois temas, é também, refletir sobre a possibilidade da escola, de fato, trabalhar à diversidade, a partir de um currículo escolar hibrido que respeite, o arcabouço social e histórico de cada sujeito que se encontra nela. Ainda que, as hipóteses iniciais deste trabalho apontem para o completo distanciamento entre o currículo formal escolar e interlocução com os saberes dos seus alunos moradores da comunidade quilombola.

No tocante a sua importância social este trabalho terá sua relevância atrelada a percepção que o Brasil ainda que seja fruto de inquestionável diversidade, étnico e cultural, porém, percebe-se, que há setores da sociedade brasileira que, sua realidade social e histórica, é em parte, invisível diante dos gestores públicos, mormente pela academia que relega esparsadas discussões sobre tais grupos, aqui as populações remanescentes de quilombos, de maneira mais particularizada, a realidade da comunidade quilombola Onze Crioulas.

\section{REVISÃO DE LITERATURA}

\subsection{Uma breve incursão histórica e semântica sobre o Quilombo}

$\mathrm{Na}$ contemporaneidade, trazer para exame a temática quilombola é, necessariamente, tratar de uma luta política, e por consequência, desemboca em uma reflexão cientifica que está sendo construída no interior da academia. LEITE (2015). O quilombo, agora, retorna ao cenário brasileiro por uma pauta que traz para emergência analítica sobre os direitos que historicamente foram negados. Sendo assim, o Quilombo- enquanto unidade de resistência de um grupo, faz emergir uma discussão na política nacional "que por sua vez exigiu a conjugação de esforços de militantes, afro-descentes e cientistas, na definição do que vem a ser 0 quilombo na atualidade e quem são os quilombolas." LEITE (2015, p. 333).

Adentrar o contexto histórico brasileiro para inserir o Quilombo enquanto 
preocupação estatal tem dois momentos estanques- primeiro momento anterior a 1988 e o segundo período é datado a partir de 1988- um século depois. NASCIMENTO, (1980); (MOURA, 1981); GOMES, (2005).

No que concerne o percurso semântico da definição de quilombo, e suas representações sociais e significações atribuídas à categoria, novamente é exigido o retorno a historiografia do Brasil.

Os primeiros achados históricos sobre a temática aqui analisada, são encontradas no livro de Gaspar Van Barleu com o título de Histórias dos feitos recentemente praticados durante oito anos no Brasil. Este livro faz referências ao Quilombo de Palmares e sua população no período compreendido entre 1634 e 1644.

Salteadores e escravos fugidos, ligados numa sociedade de latrocínios e rapinas, os quais eram dali mandados às Alagoas para infestarem as lavouras [...] A expedição contra eles, que, pouco havia, fora impedida, obtendo agora algum efeito, arruinou os Palmares grandes, onde salteadores, que compravam o ócio com latrocínios e roubos, tinham o seu valhacouto e refúgio (BARLEU, 1974, p. 273).

O livro do holandês, traz uma inequívoca desqualificação da população quilombola da época, uma vez que estes quilombolas subvertem a lógica da dominação branca e se insurgem diante de uma vida de servidão. Com similitude em seu enfoque é encontrado o livro de Sebastião da Rocha Pita, titulado, A da América Portuguesa. A obra procura elencar as justificativas para esclarecer as constantes fugas dos homens escravizados. Segundo Pita, a justificativa se assenta na necessidade que os negros tinham de viverem apartados de qualquer domínio. $O$ autor, desloca a discussão sobre as fugas das condições desumanas do trabalho forçado ao qual eram submetidos e da tirania dos ditos, senhores.

Seguindo para o período imperial brasileiro, os registros históricos sobre a construção e organização dos quilombos, o autor alemão Heirich Handelmann, em sua obra intitulada História do Brasil traz o seguinte relato: 
Ora vagavam isolados, cada um com sua família; ora se reuniam diversos num grande grupo e fundavam no âmago da mata uma aldeia em comum, em geral, umas pobres choças de palha e taipa, ao lado de uma roçada pequena para fazer plantação, o conjunto defendido, às vezes, por muralha tosca, para o caso de um imprevisto assalto; chamava-se a uma tal colônia de escravos fugidos um quilombo, ou, em outros sítios, um mocambo, ambos nomes provavelmente de origem africana. [...] existiam desde cedo, e certamente em todas as províncias do Brasil (HANDELMANN, 1982, p. 862).

Na mesma obra, traz uma nova configuração para quilombo enquanto uma sociedade solidária em defesa da liberdade dos seus moradores diante das forças repressoras do Estado. Esse vínculo de solidariedade que solidificavam, o Estado Negro fora cunhado nos porões dos navios negreiros.

[...] nos primeiros anos da invasão holandesa em Pernambuco, 1630 e seguintes,
quando se evadiu um grande número de africanos da escravidão dos portugueses,
não sabemos precisamente quando, nem como; todavia, a circunstância de se
haverem logo ajuntado e sujeitado a uma organização coletiva faz-nos supor que
eram companheiros de tribo da costa de Angola ou pelo menos malungos, isto é,
companheiros de navio, que sempre conservaram uma grande solidariedade [...] em
meados do século 17, havia o "Estado negro" assim alcançado não pequeno grau de
poder e florescimento; estava agora em condições de oferecer resistência às forças
militares da capitania de Pernambuco (HANDELMANN, 1982, p. 982).

A ressignificação de quilombo, trazida pelo historiador alemão, apresentado, Palmares como um enclave em oposição a lógica social vigente, traz para o debate, uma pequena sociedade que acolhia todos aqueles em fuga das amarras do sistema escravocrata da época. Um espaço de liberdade, resistência e convivência sob a égide da cooperação.

O período imperial do Brasil, embasados pela legislação escravista do período, os indivíduos escravizados eram apartados da vida política, social e desprovido de qualquer garantia à cidadania. Conforme MALHEIROS, (2006, p. 34), "o escravo não tinha direito de participar da vida política, pública, exército ou de qualquer participação da soberania nacional e poder público." O arcabouço legal da época sobre o tema, se alicerçava no direito romano como base para justificar 0 direito de posse dos senhores sobre os trabalhadores escravizados. Dito em mesmo sentido, "Se remontarmos ao Direito Romano antigo, aí veremos o direito de propriedade constituído sobre o escravo, quando, 
conferiu-se ao senhor, além do jus domini6 o jus potestatis. ${ }^{7}$ MALHEIRO, (2006, p. 36).

Na contemporaneidade, é tratar de uma temática que traz em sua gênese a disputa, "Um enfrentamento em torno de como o plano analítico se conecta com os planos político e normativo. Uma disputa travada entre antropólogos e historiadores" ARRUTI (2006, p. 43), uma luta que está para além dos seus direitos. A disputa tem como centralidade, o discurso sobre sua identidade. Os limites impostos por este discurso no campo semântico que trará de reconhecimento grupo de resistência desde a sua concepção.

A inexistência de políticas públicas para os negros escravizados e posteriormente para os seus descendentes. Hoje, há uma pauta de reivindicações quilombolas que perpassam pelo reconhecimento legal para as terras ocupadas, adentrando a livre manifestação de costumes, religião e formas de organização. Mais uma vez, ressignificando o quilombo enquanto lugar de "forma de organização, de luta, de espaço conquistado e mantido através de gerações, compreende-se a incidência voraz das distintas dimensões do racismo brasileiro." LEITE (2015, p. 87).

A partir da Constituição brasileira de 1988, o quilombo adquire uma significação atualizada, ao ser inscrito no art. 68, Ato das Disposições Constitucionais Transitórias- ADCT para conferir direitos territoriais aos remanescentes de quilombos que estejam ocupando suas terras, sendo-lhes garantida a titulação definitiva pelo Estado brasileiro. No entanto, o termo quilombo ou remanescente de quilombos fez emergir muitas indagações, sobre quem são esses sujeitos na atualidade, e como aparecem no cenário nacional com direitos atribuídos por um dispositivo constitucional. (FERREIRA, 2014, p. 63)

Suprimido do compêndio legislativo nacional desde 1888, a terminologia, quilombo reaparece na Carta Constitucional de 1988, sendo assim, após o fim da escravidão, o quilombo se aparta do sentido do lugar de força e

\footnotetext{
${ }^{6}$ A expressão latina se refere ao direito de dono, de proprietário.

${ }^{7}$ Expressão latina que significa direito da plenitude que se referiam na época, ao direito de vida e morte que o senhor tinha sobre seus trabalhadores escravizados.
} 
insurgente quanto o sistema vigente, porém, se sedimenta enquanto lócus de resistência em sentido mais amplo, lugar de sobrevivência diante de uma nova conjuntura econômica. Social e política na qual foram inteiramente alijados. Logo, o "o quilombo adquire a conotação de um grupo composto majoritariamente por pessoas negras, invisíveis aos olhos do Estado, no que tange à formulação de políticas públicas de reparação." FERREIRA, (2014, p. 73).

\section{2 interseção entre o currículo escolar formal, cultura, identidade e os saberes tradicionais advindos da oralidade quilombola}

Entrelaçar o currículo escolar e os saberes quilombolas é adentrar uma seara que exige o luxuoso aporte das discussões sobre cultura e identidade, já que, a conexão entre saberes e currículo está imbricada pelas relações de poder historicamente sedimentadas pela escola. Diante desta constatação, elaborar um currículo escolar que reflita os anseios, vivencias e experimentações dos sujeitos quilombolas exige um lugar se intensa negociação e conflitos. Logo, "a articulação social da diferença, da perspectiva da minoria, é uma negociação complexa, em andamento, que procura conferir autoridade aos hibridismos culturais" BHABHA, (2013, p. 21).

Uma inconteste dificuldade do lócus escolar, reside no lide com a diversidade cultural, sendo uma tendência deste ambiente, silenciar e neutralizar as diferenças, visto que, a padronização e homogeneização confere uma posição de desarme dos embates no que concerne as diferenças, sendo ela socia, étnicas, culturais, de gêneros ou históricas. MOREIRA e CANDAU, (2003, p. 161) adverte que "abrir espaço para a diversidade, a diferença e para o cruzamento de culturas constitui o grande desafio que a escola precisa [...] enfrentar."

No espaço quilombolas, as escolas ali inseridas, têm em seus currículos um lugar de contínuo embate de forças que buscam encontrar o ponto de junção entre tradição, enquanto se desconstroem as subalternidades, "articulando um processo de negociação cultural que permita à escola quilombola ser um espaço de fortalecimento de seus valores e da identidade étnica." BHABHA, (2013, p. 30). Neste embate há um profundo envolvimento entre identidade, cultura e currículo, já que, o currículo traduz as diferentes e colidentes percepções de vida social, 
"aquilo pelo qual um grupo luta." FERREIRA, (2014, p. 82). Deste modo, o currículo escolar das unidades quilombolas devem conter elementos que fortaleçam a sua identidade coletiva e individual diante da tessitura social. Porém, Bauman (2005) lembra que "o campo de batalha é o lar natural da identidade. Ela só vem à luz no tumulto da batalha [...] é uma luta simultânea contra a dissolução e a fragmentação" BAUMAN, (2005. p. 74). Assim, é possível coligir que mormente que o embate, também, seja o "lar natural" do currículo.

O currículo é marcado por conflitos, negociações, disputas que estão diretamente vinculados às relações de poder. Assim, currículo, cultura e identidade estão implicados de forma permanente em lutas pela afirmação e legitimação de vozes silenciadas, visto que, grupos subordinados tentam resistir à imposição de significados que mantêm os interesses dos grupos hegemônicos. (FERREIRA, 2014, p. 83)

Diante deste panorama apresentado, o currículo da escola quilombola
com vistas a preservar e sedimentar os saberes tradicionais baseados
na oralidade desta comunidade, deve se apresentar a partir de um
modelo hibrido que "o constitui oferece novas possibilidades para se
refletir sobre a complexidade dos processos culturais, políticos e sociais
que o configuram." DUSSEL (2002, p. 96$)$.

Cabe a ressalva que a definição de hibridismo permite adentrar uma grande variabilidade de perspectiva analítica que permita reconhecer e "compreender os processos de reconhecimento, de legitimação e de apropriação das políticas curriculares nas diferentes instâncias pelas quais transitam até sua efetiva implementação no local a que se destina." DUSSEL (2002, p. 98).

Portanto, a construção de uma política curricular que atendam as escolas quilombolas passeia por diversos fragmentos de exame da instituição que é sua mantenedora, aqui, especificamente, a Prefeitura Municipal do Cabo de Santo Agostinho, que tem o poder de decidir e avaliar os itens que podem ser contemplados e aqueles que devem ser rechaçados de uma proposta curricular, "cujo objetivo maior é reconhecimento, visibilidade, integração entre conhecimentos oriundos de uma cultura historicamente subalternizada, portanto, 
negada, quando não estereotipada no currículo dito oficial." (FERREIRA, 2014, p. 83).

\subsection{Preâmbulo histórico da Comunidade Quilombola Onze Negras}

Encetar a apresentação sobre a Comunidade em destaque, exige do pesquisador, a eleição da metodologia e teorias que alicerçarão tal exposição. Deste modo, é necessário, especialmente, examinar detidamente esses caminhos metodológicos para garantir o repertório adequado de ferramentas cientificas que oportunize uma análise cientifica criteriosa.

Cientes deste percurso e cuidado na escolha do método, esbarra-se na intricada encruzilhada ao se propor apresentar o histórico de uma dada comunidade remanescente de quilombo. Assim, dois caminhos científicos se mostram promissores: i) segue-se pelo reconto de uma história já apresentada ou; ii) busca-se uma análise e construção histórica pautada na relação- pesquisador e comunidade.

Especificamente, no trato do percurso histórico da Comunidade Quilombola será utilizado o reconto através das produções acadêmicas anteriores $^{8}$, assim como, a produção engendrada pela própria Comunidade Quilombola9.

\footnotetext{
8 "Trata-se da dissertação de autoria de Beatriz Hochmann Béhar, com o título: Que Tal a Gente dar o Nome de Onze Negras? O papel das narrativas na inserção política e cultural da Comunidade Quilombola Onze Negras"; A dissertação: Território e identidade: conflitos socioambientais na comunidade quilombola onze negras Cabo de Santo Agostinho/PE de autoria de Elielton Alves de Albuquerque defendida em 2011 na Universidade Federal de Pernambuco.

9 Segundo, SILVA ( 2017, p. 60), O livro denominado: "Onze Negras: Comunidade quilombola", (Cabo de Santo Agostinho, PE: 2007) é resultado da própria luta por reconhecimento que foi e é protagonizada pela Comunidade Quilombola Onze Negras; o volume serviu e serve, inclusive, como forte instrumento de afirmação da identidade dos quilombolas daquela comunidade. Nele estão presentes apontamentos das reminiscências que contribuíram e contribuem para a construção da sua identidade. Por isso mesmo, para estabelecermos um histórico sobre a comunidade em questão, optamos por nos apoiar nesta obra. A nossa escolha se dá, sobretudo, quando consideramos a necessidade da participação efetiva da Comunidade Quilombola Onze Negras na construção das (es)histórias que falam sobre ela.
} 
A Comunidade remanescente de Quilombo em tese, tem seus descendentes a partir de sujeitos escravizados trabalhadores saídos do interior de Pernambuco para trabalharem na Usina de moagem de cana do Cabo de Santo Agostinho:

O início da formação da Comunidade Onze Negras remonta ao ano de 1940, quando algumas famílias migraram da capital e do interior do Estado de Pernambuco para o Cabo de Santo Agostinho com o intuito de trabalhar nas terras da Usina Santo Inácio. À época a região era utilizada para o cultivo de cana-de-açúcar, necessitando de mão-de-obra para plantio, irrigação e corte de cana. Os imigrantes não trabalhavam apenas no campo, alguns realizavam trabalhos domésticos na casa do dono da usina, sendo essas as condições para que as famílias fixassem moradia na região. (ONZE NEGRAS, 2007, p. 19).

[...] A origem da comunidade remonta à vocação histórica de Pernambuco para o cultivo da cana de açúcar [...] na década de 40, algumas famílias migraram para a região com o intuito de trabalhar [...] no Engenho Trapiche. [...] e "com o passar dos anos, as famílias que residiam na região se casaram entre si, originado três grandes famílias" que descendiam de ex escravos da região. (BEHAR, 2015, p, 8)

O declínio da economia canavieira e açucareira local, não fragilizou o crescimento desta comunidade com amplos vínculos que se localizou nas áreas do antigo Engenho Trapiche, que, estava locado em terras públicas. A ampliação da BR 101 Sul e o posterior crescimento da economia local, exigiram a retirada das famílias da localidade.

[...] com a instalação do complexo industrial e o desenvolvimento econômico do Cabo do Santo Agostinho, no final da década de 60, foi necessária a abertura de rodovias federais que ligaria o município à capital. Isso obrigou as famílias a desocuparem as terras [...]. Nesse processo de desocupação, os moradores receberam uma indenização do Governo do Estado que poderia ser realizada através do pagamento em dinheiro [...]. Foi desse modo que a comunidade quilombola do Cabo de Santo Agostinho comprou suas terras [...]. (ONZE NEGRAS, 2007, p. 21).

As indenizações foram utilizadas para compras de lotes de terras, distantes dos equipamentos básicos públicos do Município do Cabo de Santo Agostinho, essa condição se tornou um importante desmobilizador da comunidade. Cabe a ressalva acerca das diversas denominações ${ }^{10}$ dadas a localidade em destaque.

10 As reminiscências próprias da oralidade local explicam que inicialmente a Comunidade 
Essas nominações trazem importantes representações simbólicas do processo histórico e social vivenciados pelos moradores desta comunidade.

O espaço remanescente de quilombo Onze Negras fica entre a BR 101 sul, após o Hospital Dom Helder e na sua parte dianteira está a Rodovia Mario Covas, porém, a comunidade só tem acesso a localidade pela BR- 101 SulDistrito Industrial Diper, Cabo de Santo Agostinho - PE. A Figura 1 mostra a partir de uma visão de satélite local que está inserida essa comunidade no município do Cabo de Santo Agostinho no litoral sul de Pernambuco.

O contexto histórico para a sua formação é detalhada em obra escrita pelos próprios moradores como forma de trazer para além da oralidade a perpetuação da sua biografia coletiva.

\begin{abstract}
O início da formação da Comunidade Onze Negras remonta ao ano de 1940, quando algumas famílias migraram da capital e do interior do Estado de Pernambuco para o Cabo de Santo Agostinho com o intuito de trabalhar nas terras da Usina Santo Inácio. Á época a região era utilizada para o cultivo de cana-de-açúcar, necessitando de mão-de-obra para plantio, irrigação e corte de cana. Os imigrantes não trabalhavam apenas no campo, alguns realizavam trabalhos domésticos na casa do dono da usina, sendo essas as condições para que as famílias fixassem moradia na região. (ONZE NEGRAS, 2007, p. 19).
\end{abstract}

Uma localidade de difícil acesso com estrada de barro e rodeada por vegetação nativa, denominada uma comunidade rural, porém, apartada dos direitos fundamentais básicos, vivendo mais "isolados da realidade vivida por aqueles que ocupavam a área mais central do município do Cabo de Santo Agostinho". SILVA (2017, p. 63).

chamava-se Burrama e posteriormente "Pista Preta" devido ao uso do Piche utilizado no processo de asfaltamento da rua principal desta localidade. Inclusive, esse nome designa os ônibus da Cooperativa de Transporte Complementar do Município do Cabo de Santo Agostinho. Após o ano de 1999 com a fundação da Associação de bairros da Comunidade, houve a mudança formal para" Onze Negras". Em homenagem ao time da localidade- Onze Negros. 
Revista Ibero-Americana de Humanidades, Ciências e Educação

Produção e democratização do conhecimento na lbero-América

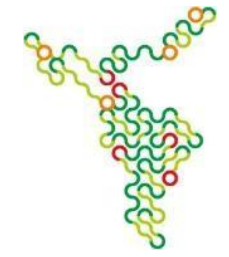

Figura 1- Localização por satélite da Comunidade Onze Negras

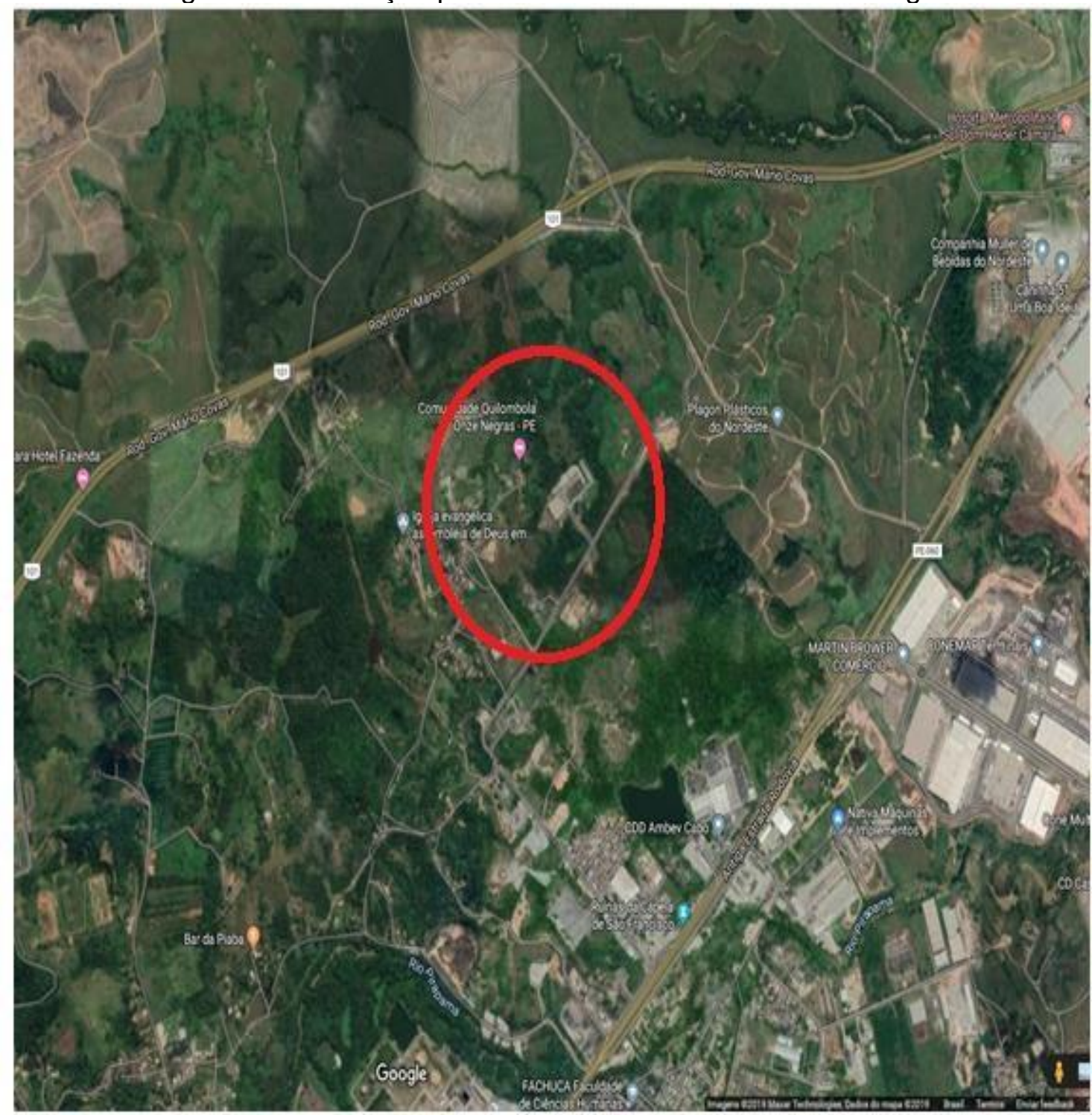

Fonte: Google Maps, 2019.

\section{METODOLOGIA}

Foi realizado uma pesquisa bibliográfica e documental sobre o tema sopesado com a intencionalidade de colher as informações que pudesse responder os objetivos iniciais deste trabalho, assim como, buscar subsídios metodológicos e teóricos para o aprofundamento temático, com vistas, ao atendimento à dinâmica dissertativa seguinte abrolhado a partir da inquietação inicial que culminou com este artigo. 


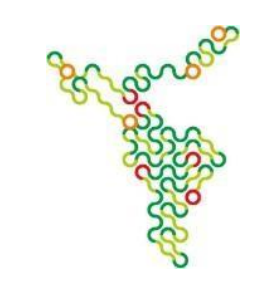

\section{CONSIDERAÇÕES FINAIS}

A abordagem do referido tema em epítome, trouxe o entendimento que 0 processo de construção das tradições orais das comunidades quilombolas, especialmente da Quilombola de Onze Negras se se compõe como resultado de cabedal rico e real das vivências e lutas pela busca pelo reconhecimento da citada Comunidade, em vários aspectos se assemelha a luta travada por diversas Comunidades Quilombolas pelo país. No entanto, as especificidades da Comunidade Onze Negras fazem deste universo uma importante arcabouço civilizatório e cultural brasileiro.

\section{REFERÊNCIAS}

ALBUQUERQUE JR, Durval Muniz de. Um leque que respira: Michel Foucault e a questão do objeto em história. In: PORTOCARRERO, Vera e CASTELO BRANCO, Guilherme (Org.). Retratos de Foucault. 3aㅡ ed. Rio de Janeiro: NAU, 2012.

ALMEIDA, Alfredo Wagner Berno de. Os Quilombos e as Novas Etnias. In: O'DWYER, Eliane Cantarino (Org.). Quilombos: Identidade étnica e territorialidade. Rio de Janeiro: Ed. FGV, 2002.

Terras de Quilombo, Terras Indígenas, "Babaçuais Livres", "Castanhais do Povo", Faxinais e Fundos de Pasto: Terras Tradicionalmente Ocupadas. Manaus: PPGSCA-UFAM, 2006.

ÁlVARO, J. L.; GARRIDO, A. Psicologia Social. Perspectivas Psicológicas e Sociológicas. São Paulo: McGraw-Hill, 2006.

BAUMAN, Zygmunt. Comunidade: a busca por segurança no mundo atual. Rio de Janeiro: Zahar, 2003.

COSTA, João Batista de Almeida. A (des)invisibilidade dos Povos e das Comunidades Tradicionais: A produção da identidade, do pertencimento e do modo de vida como estratégia para efetivação de direito coletivo. Montes Claros: Unimontes, 2009.

FERNANDES, Ricardo Cid. et al. (Org.). Relatório Antropológico: Comunidade Quilombola João Sura - Adrianópolis/PR, 2007. Documento resultante do Convênio UFPR/INCRA com base no projeto Direito à Terra e Comunidades Quilombolas no Paraná: elaboração de estudos históricos e antropológicos. Curitiba. Relatório técnico, 2007. 
FERNANDES, Florestan. O Negro no Mundo dos Brancos. São Paulo: Difel, 1972.

FIGUEIREDO, Luiz Afonso Vaz de. (2001.) Iporanga: dados \& históricos. In: Jornal O Progresso, 27/01/2001, no 01. São Paulo.

FREIRE, Paulo. Pedagogia da Autonomia. $7^{a}$ ed. São Paulo: Paz e Terra, 1996.

GOMES, Flávio dos Santos. Sonhando com a Terra e Construindo a Cidadania. In: PINSKY, Jaime; PINSKY, Carla Bassanezi (Org.). História da Cidadania. São Paulo: Ed. Contexto, 2005.

Histórias de quilombolas: mocambos e comunidades de senzalas no Rio de Janeiro, século XIX. Rio de Janeiro: Companhia das Letras, 2006.

LEITE, Ilka Boaventura. Os quilombos no Brasil: Questões conceituais e normativas. Publicado no sítio eletrônico do Núcleo de Estudos sobre Identidade e Relações Interétnicas - 2000, NUER/UFSC. Disponível no endereço < > Acesso em 17/12/2019.

LÉSARD-HÉBERT et al. Investigação qualitativa: fundamentos e práticas. Lisboa: Instituto Piaget, 2016.

LOVELL, Peggy A. (org.). Desigualdade Racial no Brasil Contemporâneo. Belo Horizonte: UFMG//CEDEPLAR, 2011.

LUDCKE, M.; ANDRÉ, M. Pesquisa em Educação: abordagens qualitativas. São Paulo: EPU, 2009.

Silva, Jairo Hely Comunidade Quilombola Onze Negras - identidade e reconhecimento em questão / Jairo Hely Silva. - 2017. 